\title{
Anopheles arabiensis and Anopheles funestus biting patterns in Dielmo, an area of low level exposure to malaria vectors
}

\author{
Souleymane Doucoure ${ }^{1 *} \mathbb{D}$, Omar Thiaw ${ }^{1,2}$, Amélé N. Wotodjo ${ }^{1}$, Charles Bouganali ${ }^{1}$, Nafisatou Diagne ${ }^{1}$, \\ Philippe Parola ${ }^{3,4}$ and Cheikh Sokhna $a^{3,4}$
}

\begin{abstract}
Background: In Dielmo, Senegal, the widespread use of long-lasting insecticidal nets has decreased both the incidence of malaria and the density of the Anopheles population. However, persistent low-level malaria transmission may hamper efforts to eliminate the disease. Therefore, continuous monitoring of the vector population is needed in order to improve knowledge of Anopheles biting behaviour and to readjust control interventions.

Methods: In 2015, Anopheles were collected every month for a whole year and each specimen was identified using morphological and molecular techniques. The biting pattern of each species was analysed according to night (7 pm7am) and morning (7am-11am) periods, the place of biting and the season. The ELISA CSP technique was used to assess the Plasmodium falciparum sporozoite rate to evaluate the entomological inoculation rate (EIR).

Results: Anopheles arabiensis and Anopheles funestus sensu stricto were found to be the main vectors biting humans. Overall, the biting rate was low, at 3.84bites per night (bpn) and 1.27 bites per morning (bpm), respectively $(\mathrm{IRR}=3.04, \mathrm{Cl}[1.84-5.00], \mathrm{p}<0.001)$. The EIR was 2.51 and 5.03 infectious bites per year during the night and morning, respectively. During the night, the An. arabiensis and An. funestus biting rate was $1.81 \mathrm{bpn}$ and $1.71 \mathrm{bpn}$, respectively (IRR=0.95, $\mathrm{Cl}[0.46-1.92], \mathrm{p}=0.88$ ). During the morning, their density decreased to $0.51 \mathrm{bpm}$ and $0.73 \mathrm{bpm}$ for An. arabiensis and An. funestus, respectively (IRR $=1.47, \mathrm{Cl}[0.58-3.71], \mathrm{p}=0.41)$. During the night and the morning, no specific trend of indoor or outdoor biting was observed in the dry and rainy season for both vectors.

Conclusion: This study highlighted low level Anopheles nocturnal and diurnal biting and the associated risk of malaria transmission. It showed also the influence of the season on the indoor and outdoor biting pattern, indicating that the human population could be exposed all year round to a low level of Anopheles bites. Control programmes should increase awareness of the use of bed nets throughout the year and promote the development and implementation of complimentary tools to target Anopheles biting shortly after dawn when people are still indoors and outside the bed nets.
\end{abstract}

Keywords: Malaria, Senegal, Anopheles arabiensis, Anopheles funestus, Indoor, Outdoor, Night, Morning, Season

\section{Background}

The incidence of malaria has decreased significantly over the last 15 years [1]. The decrease in incidence of the

\footnotetext{
*Correspondence: souleymane.doucoure@ird.fr

${ }^{1}$ VITROME, Campus International UCAD-IRD, Dakar, Sénégal

Full list of author information is available at the end of the article
}

disease was made possible due to combined strategies targeting both the Plasmodium parasites and Anopheles vectors. This situation has made it possible to envisage the elimination of malaria in some endemic countries. However, malaria still remains a public health problem, as no significant progress has been made in reducing the incidence of the disease further in recent years [1]. This 
situation highlights the need to reinforce malaria surveillance, particularly to improve the control of Anopheles vectors.

Universal coverage of long-lasting insecticidal nets (LLINs) is currently the primary and most effective strategy for controlling Anopheles and consequently transmission of Plasmodium parasites [2]. The use of LLINs represents a powerful barrier against Anopheles mosquitoes biting and resting indoors. For this reason, the efficacy of control strategy based on LLINs use is limited when the human populations are not in bed during the period when Anopheles are host- seeking. Therefore, socio-environmental changes that bring human to stay outside sleeping places, where LLINs could not be used, could make a portion of the population vulnerable to Anopheles bites and sustain malaria transmission even at very low levels $[3,4]$. On the other hand, the complex ecology of Anopheles may have an impact upon the effectiveness of LLINs. Indeed, it is well known that most of the efficient vectors of malaria in endemic areas have developed particular behaviour enabling them to avoid insecticide-treated nets and to feed safely on the human population [5]. This avoidance of LLINs by Anopheles is currently marked by significant outdoor feeding after the introduction of bed nets in some endemic areas $[6,7]$. In addition to increased outdoor biting, Anopheles may adapt their biting time to specific periods during which the LLINs may not be used by the population. It is now observed that Anopheles have crepuscular and diurnal host-seeking activity which coincide, respectively, with the periods just before people go to sleep under their bed nets and just after waking up when they move outside the bed nets [8-10]. Therefore, despite a decrease in human exposure $[7,11]$ resulting from general coverage and a high level of bed net use, Anopheles behaviour could reduce the effectiveness of LLINs as people remain unprotected when mosquitoes shift their biting times or locations $[9,12]$. This situation could, therefore, represent a challenge for malaria control, particularly in areas where vector controls have been implemented to eliminate the disease. Thus, close monitoring of vectors is needed in order to determine the particular biting behaviour of Anopheles that could put the human population at risk, despite the use of LLINs.

\section{Methods}

\section{Study area}

The village of Dielmo is located in the Fatick region, $280 \mathrm{~km}$ southeast of Dakar capital of Senegal, West Africa. In 2015, the population of Dielmo was estimated to 481 habitants distributed in 42 households. The climate is typical Sudanese-Savanna and the rainy season occurs from June/July to October/November. The annual average rainfall ranges from 400 to $900 \mathrm{~mm}$ and the mean temperature ranges from 22 to $35{ }^{\circ} \mathrm{C}$. LLINs universal coverage strategy began in 2008 with three general renewal operations in 2011, 2014, 2016 and 2019. PermaNet $^{\circledR}$ 2.0 LLINs (active ingredient: deltamethrin) were used in 2008, 2011 and 2014 universal coverage campaigns. In 2016 campaign, a mix of PermaNet ${ }^{\circledR} 2.0$ and Olyset Net $^{\circledR}$ (active ingredient: permethrin) LLINs was used. In the last campaign in 2019, the coverage was done with Yorkool ${ }^{\circledR}$ (active ingredient: deltamethrin) LLINs.

\section{Field study and laboratory processing of mosquitoes}

The human landing catch (HLC) technique was used to collect Anopheles mosquitoes from January 2015 through December 2015. Every month, two households were used to trap mosquitoes over three consecutive nights $(7 \mathrm{pm}$ to 7am) and morning (7am to 11am). These two households, $200 \mathrm{~m}$ apart, represent mosquitoes collection sites since the beginning of Dielmo Project in 1990 [13] until now and remained unchanged throughout the course of the study. During the night (7 pm to 7am) in each of the two sites, hourly HLC were made on two adults volunteers, one positioned inside the concession (indoor) and the other outside the concession (outdoor). In each location, indoors and outdoors, the collector was changed every $6 \mathrm{~h}$. At $7 \mathrm{pm}$, in one of the collection site, the HLC were continued until $11 \mathrm{am}$, thus representing the morning collection. The collection procedure in the morning was the same as the one applied in the night.

Mosquitoes were identified morphologically using a dichotomous key described by Gilles and De Meillon [14]. In addition, a one-step PCR method using intentional mismatch primers (IMPs) was used to identify sibling species of the Anopheles gambiae complex [15] and the Anopheles funestus group [16] collected during the entire study. The crushed head and thorax was used to detect the presence of Plasmodium falciparum circumsporozoite protein (CSP) antigen in each Anopheles specimen using the ELISA-CSP technique [17].

\section{Rainfall data collection}

During the entire study period, daily rainfall was recorded manually in Dielmo site to define a mean level of rainfall during the rainy and dry seasons.

\section{Data analysis}

Anopheles gambiae complex and An. funestus group are the only malaria vectors involved in Plasmodium transmission in Dielmo. Thus, the human biting rate (HBR) and the entomological inoculation rate (EIR) were evaluated taking account only the species that belong to $A n$. gambiae complex and An. funestus group. The HBR, 
which represents the density of the Anopheles was calculated by dividing the number of mosquitoes collected by the number of person-night/morning during the sampling period. Thus, throughout the course of the study, total Anopheles density during the night and morning was evaluated as well as the hourly biting rate. The EIR was obtained by multiplying the HBR by the ratio of the number of infected mosquitoes by the number of total mosquitoes screened for the presence of P. falciparum.

The density of the Anopheles was analysed according to the time of biting (night/morning), the place of biting (indoor/outdoor) and the season (dry/rainy) using a GLM (generalized linear model) with a negative binomial distribution. Analyses were performed using Stata Software, version 11.0 (College Station, Texas, USA).

\section{Results}

\section{Anopheles species composition}

A total 12 person-nights and 6 person-mornings were used to collect mosquitoes each month, representing a total of 144 person-nights and 72 person-mornings in the night and the morning, respectively, during the entire investigation. This resulted, from January to December 2015, in the collection of 680 female Anopheles according the following distribution: 588 (86.49\%) specimens in the night and $92(13.50 \%)$ in the morning. Morphological identification enabled us to highlight the presence of Anopheles ziemanni, Anopheles pharoenis and species which belong to the An. gambiae complex and An. funestus group. In order to have the precise species composition of the Anopheles population, molecular identification was carried out on specimen of An. gambiae complex and $A n$. funestus group. During the night, An. arabiensis and An. funestus represented 261 (44.38\%) and 247 (42\%) of the collection, respectively. At the same time, Anopheles coluzzii and An. gambiae sensu stricto (s.s.), both of which belong to the An. gambiae complex, were found in the proportions of $26(4.42 \%)$ and 20 (3.40\%), respectively. However, PCR did not allow us to identify nine (1.53\%) specimens of An. gambiae sensu lato (s.l.) caught during the night. Anopheles ziemani and An. pharaonis represented $16(2.72 \%)$ and nine $(1.53 \%)$, respectively, of the entire night-time collection. In the morning collection, 53 An. funestus (57.60\%), 37 An. arabiensis (40.21\%) and two An. coluzzii (2.17\%) were collected.

\section{Anopheles biting pattern}

Overall, from $7 \mathrm{pm}$ to $11 \mathrm{am}$, the biting rate was at 2.56 bites/person. The HBR was significantly different during the night and the morning with 3.84 bites per night (bpn) and 1.27 bites per morning (bpm) (Incidence rate ratio $(\mathrm{IRR})=3.04,95 \%$ confidence intervals [CI] [1.845.00], $\mathrm{p}<0.001)$, respectively. Anopheles arabiensis and
An. funestus were the main species biting humans both at night and morning. During the night, An. arabiensis and An. funestus had almost the same biting rate, 1.81 bpn and $1.71 \mathrm{bpn}$, respectively (Fig. 1) $(\mathrm{IRR}=0.95, \mathrm{CI}$ [0.46-1.92], $\mathrm{p}=0.88)$. During the morning, the biting rate of An. funestus (0.73 bpm) was slightly higher than that of An. arabiensis $(0.51 \mathrm{bpm})(\mathrm{IRR}=1.47$, CI [0.583.71 ], $\mathrm{p}=0.41$ ) (Fig. 1). However, during the whole study period and both during the morning and the night, there was no significant difference between the biting rate of An. arabiensis and An. funestus (IRR $=1.06$ [0.61-1.82]; $\mathrm{p}=0.83$ ). At the same time, the biting rate the biting rate of An. arabiensis was significantly higher than that of An. coluzzii (IRR $=0.09$, CI [0.03-0.24]; p < 0.001) and An. gambiae s.s. $(\mathrm{IRR}=0.06, \mathrm{CI}[0.02-0.19] ; \mathrm{p}<0.001)$. The An. coluzzii biting rates was $0.18 \mathrm{bpn}$ and $0.02 \mathrm{bpm}$, whereas An. gambiae s.s. biting activity was noticed only during the night (0.13 bpn) (Fig. 1).

\section{Anopheles hourly activity}

Anopheles funestus and An. arabiensis aggressiveness increased progressively throughout the first half of the night (7 pm-12 midnight) reaching 0.20 and 0.17 bites per hour, respectively. During the second part of the night (12 midnight-7am), two peaks were observed for both vectors (Fig. 2). The first peak was recorded between 1am and 2am with an HBR of 0.29 and 0.31 bites per hour for An. funestus and An. arabiensis, respectively. The second peak was observed at the end of the second part of the night, between $4 \mathrm{am}$ and $5 \mathrm{am}$ for An. funestus (0.24 bph) and between $5 \mathrm{am}$ and 6am for An. arabiensis (0.17 bph). The HBR of An. coluzzii and An. gambiae s.s. was very low and constant, despite weak peaks of activity

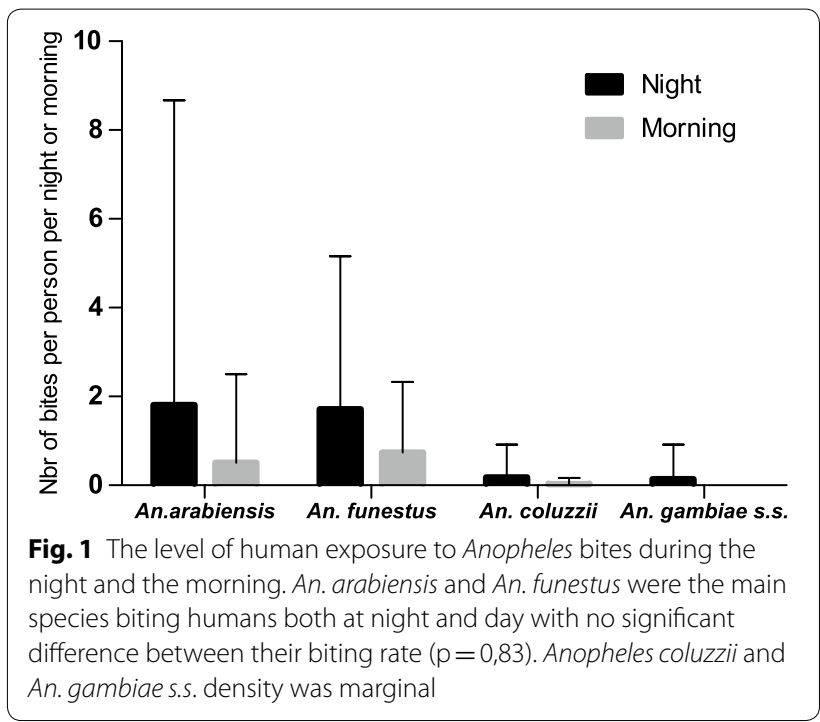


- An. arabiensis Indoor

--- An. arabiensis Outdoor

- An. funestus s.s Indoor

...- An. funestus s.s Outdoor

- An. coluzzii Indoor

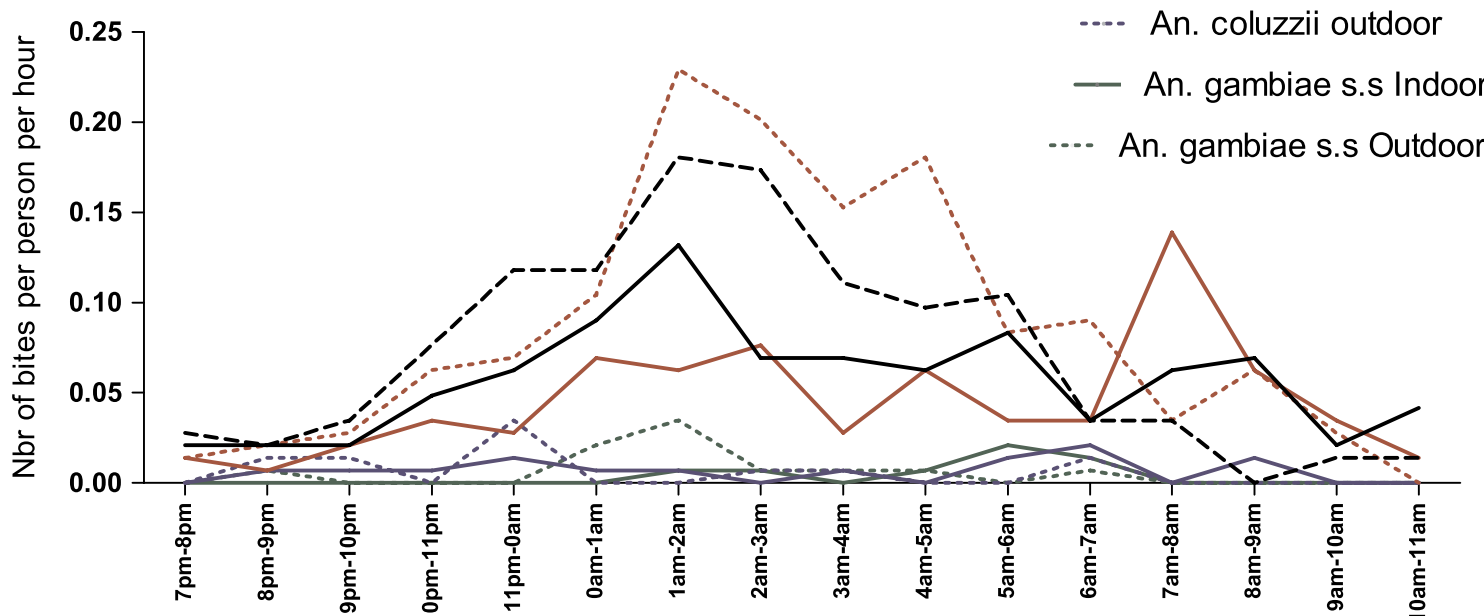

Fig. 2 Anopheles hourly aggressiveness from $7 \mathrm{pm}$ to $11 \mathrm{am}$. Two peaks of activity involving An. arabiensis and An. funestus were observed during the first and second parts of the night. A third peak was also observed during the morning. No significant difference was observed between the activity of the first and the second part of the night $(p=0.46)$ and the morning $(p=0.97)$

occurring between $11 \mathrm{pm}$ and 12 midnight, between 6am and $7 \mathrm{am}$ for $A n$. coluzzii, and between 1am and 2am for An. gambiae s.s. The peak of activity in morning was observed between 7am and 8am with an HBR of 0.17 bites per hour and 0.09 bite per hour for An. funestus s.s. and An. arabiensis, respectively (Fig. 2) However, when all four species are considered, the hourly activity was not different between the first and de second part of the night (IRR $=2.50$; CI [0.21-29.59]; $\mathrm{p}=0.46)$, and between the first part of the night and the morning $(I R R=0.94$; CI [0.03-25.53]; $p=0.97$ ). Overall, no significant difference was observed between the night and the morning $(I R R=0.50$; CI [0.03-7.46]; $\mathrm{p}=0.62$ ) (Fig. 2).

\section{Anopheles indoor and outdoor biting activity}

The influence of the season (dry season, from December to June with $0.5 \mathrm{~mm}$ of cumulative rainfall; rainy season from July to November with $813.38 \mathrm{~mm}$ of cumulative rainfall) on Anopheles biting patterns was also evaluated by taking into account the place of biting (indoor/outdoor), the species and period (night/morning). Overall during the study, in the night, the HBR was higher during the rainy season (2.520 bpn) compared to the dry season (1.32 bpn) (IRR =2.66; CI [1.47-4.80]; $\mathrm{p}=0.001)$. An. arabiensis outdoor biting rate $(2.19 \mathrm{bpn})$ was higher than that recorded indoor (1.43 bpn) despite the fact that this trend of exophagic behaviour was not significant $(\mathrm{IRR}=1.53$; CI [0.56-4.19]; $\mathrm{p}=0.40) . A n$. funestus had a HBR of 0.95 bpn and $2.47 \mathrm{bpn}$ indoors and outdoors, respectively (IRR $=2.57$; CI [0.90-7.37)]; $\mathrm{p}=0.08)$. The An. coluzzii biting rate was identical indoors and outdoors (0.18 bpn); An. gambiae s.s. showed nearly the same biting rates indoors $(0.11 \mathrm{bpn})$ and outdoors (0.16 bpn) (Fig. 3a). When the season and the biting place are combined, An. funestus did not displayed any significant exophagic behaviour neither in the dry season $(\operatorname{IRR}=3.12$; CI $[0.68-14.28)], \mathrm{p}=0.14$ ), nor in the rainy season (IRR $=2.27, \mathrm{CI}[0.50-10.32)]$, $\mathrm{p}=0.28)$. The same trend was observed with $A n$. arabiensis in the rainy $(\mathrm{IRR}=1.5, \mathrm{CI}[0.35-6.29], \mathrm{p}=0.57)$ and dry season $(\mathrm{IRR}=1.62$; CI $[0.34-7.58] ; \mathrm{p}=0.54)$ (Table 1).

During the morning, there was no significant difference $(\mathrm{IRR}=0.91 ; \mathrm{CI}[0.39-2.10] ; \mathrm{p}=0.84)$ between aggressiveness during the rainy $(0.51 \mathrm{bpm})$ and the dry season $(0.76 \mathrm{bpm})$. The An. arabiensis indoor and outdoor HBR was at $0.75 \mathrm{bpm}$ and $0.25 \mathrm{bpm}$, respectively (IRR $=0.33$; CI [0.072-1.54]; $\mathrm{p}=0.16$ ) (Fig. $3 \mathrm{~b}$ ) and no significant difference was found $(\mathrm{IRR}=0.51$; CI $[0.14-1.82] ; \mathrm{p}=0.30$ ) between the indoors $(0.97 \mathrm{bpm})$ and the outdoors 


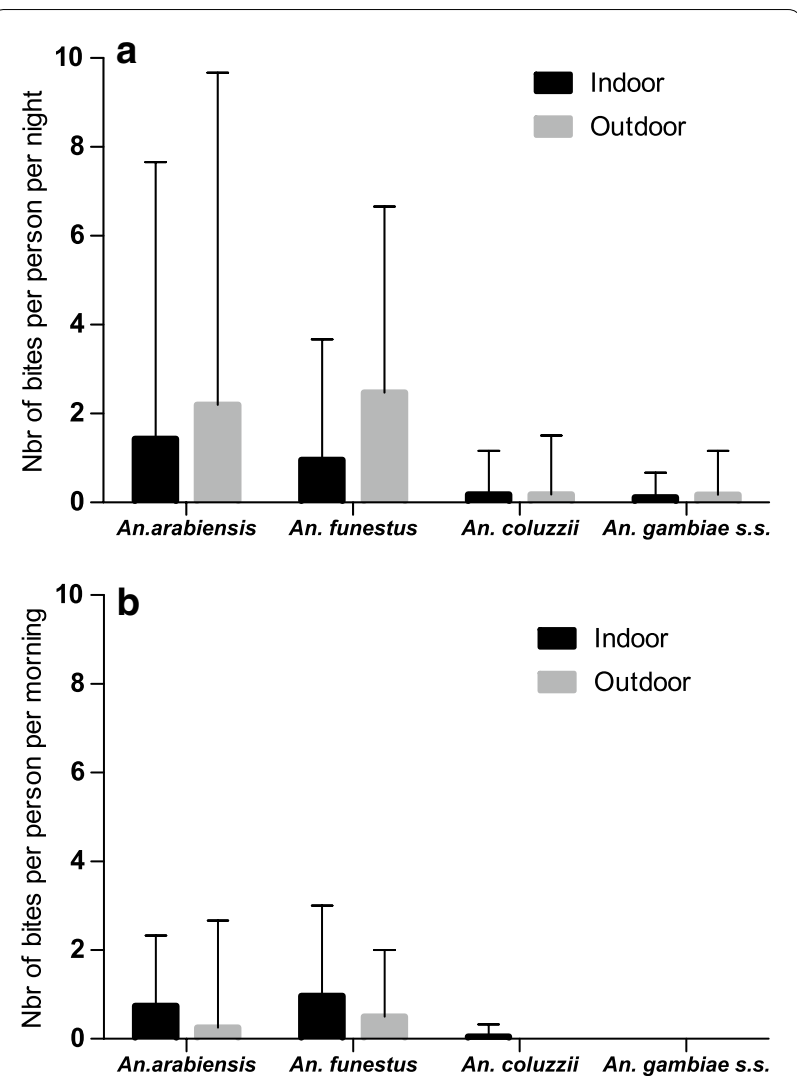

Fig. 3 a Anopheles indoor and outdoor biting rates during the night. During the night, any significant outdoor biting compared to indoor was observed for An. arabiensis $(p=0.404)$ and An. funestus $(p=0,08)$. $3 \mathrm{~b}$ Anopheles indoor and outdoor biting rates during the day. During the morning, any significant outdoor biting compared to indoor was for An. arabiensis $(p=0.33)$ and An. funestus $(p=0.30)$

(0.5 bpm) regarding the aggressiveness of An. funestus (Fig. 3b).

During morning, in the dry season, An. arabiensis biting activity was only observed indoors $(0.36 \mathrm{bpm})$ area while in the rainy season it was $0.38 \mathrm{bpd}$ and $0.25 \mathrm{bpm}$ indoors and outdoors, respectively (IRR $=0.64$; CI [0.094.33]; $\mathrm{p}=0.65$ ) (Table 2). In the dry season, the indoor and outdoor aggressiveness of An. funestus was $0.83 \mathrm{bpm}$ and $0.27 \mathrm{bpm}(\mathrm{IRR}=0.33 ; \mathrm{CI}[0.06-1.68] ; \mathrm{p}=0.18)$, respectively. In the rainy season, its aggressiveness was at $0.13 \mathrm{bpm}$ and $0.22 \mathrm{bpm}$ indoors and outdoors, respectively (IRR $=1.6$; CI [0.16-15.93]; $\mathrm{p}=0.68)$ (Table 2). An. coluzzii aggressiveness was only observed indoors and only during the dry season $(0.055 \mathrm{bpm})$ (Table 2$)$.

\section{Anopheles EIR}

Throughout the whole study, only two specimens were found to be using to the ELISA-CSP test: one An. arabiensis and one An. funestus collected during the night and the morning, respectively. Both positive specimens were caught outdoors, during the dry season. The EIR was, therefore, estimated to be 2.51 infectious bites per person per year during the night compared to 5.03 infectious bites per person per year during the morning.

\section{Discussion}

In Dielmo, malaria vectors have been monitored since 1990 [18]. The results of this investigation confirm the dominance of An. arabiensis and An. funestus as the main vectors of malaria and the collapse of the Anopheles population that has been observed since the introduction of universal LLIN coverage [7]. In addition to An. funestus biting humans during daylight, as previously described [9], this study shows, for the first time, the diurnal host-seeking activity of An. arabiensis and An. coluzzii. Therefore, in Dielmo, three main malaria vectors now demonstrate diurnal host-seeking behaviour. The widespread introduction of insecticide-based control likely explains the host-seeking activity of Anopheles shortly before dusk and after dawn $[9,10,19,20]$. Universal LLIN coverage has been the only strategy implemented to control the Anopheles vector since 2008 and has been suspected of contributing to the daytime behaviour of $A n$. funestus [9]. To date, there has been no thorough investigation into the daytime behaviour of Anopheles vectors. It is possible that this behaviour is due to the plasticity of vectors that continue their host-seeking activity during daylight when they could not feed at night due to the use of LLINs. On the other hand, Anopheles mosquitoes have

Table 1 Anopheline indoor and outdoor biting rate during the night according the season. Each value represents the number of bites per person per night, indoor or outdoor

\begin{tabular}{|c|c|c|c|c|c|c|c|c|}
\hline & \multicolumn{8}{|l|}{ Night } \\
\hline & \multicolumn{4}{|l|}{ Dry season } & \multicolumn{4}{|l|}{ Rainy season } \\
\hline & An.arabiensis & An.funestus & An.coluzzii & An. gambiae & An.arabiensis & An.funestus & An.coluzzii & An. gambiae \\
\hline Indoor & $0.40(p=0.54)$ & $0.34(p=0.14)$ & $0.11(p=0.57)$ & $0.01(p=0.99)$ & $1.02(p=0.57)$ & $0.61(p=0.28)$ & $0.06(p=0.64)$ & $0.09(p=0.68)$ \\
\hline Outdoor & 0.65 & 1.08 & 0.04 & 0 & 1.54 & 1.38 & 0.13 & 0.16 \\
\hline
\end{tabular}

Each value represents the number of bites per person per night, indoor or outdoor. No significant feeding behaviour according the place of biting was observed for both vector during the dry and the rainy season 
Table 2 Anopheline indoor and outdoor biting rate during the morning according the season

\begin{tabular}{|c|c|c|c|c|c|c|c|c|}
\hline & \multicolumn{8}{|l|}{ Morning } \\
\hline & \multicolumn{4}{|l|}{ Dry season } & \multicolumn{4}{|l|}{ Rainy season } \\
\hline & An .arabiensis & An. funestus & An. coluzzii & An. gambiae & An. arabiensis & An funestus & An. coluzzii & An. gambiae \\
\hline Indoor & $\begin{array}{l}0.36 \\
-\end{array}$ & $0.83(p=0.18)$ & 0.05 & 0 & $0.38(p=0.65)$ & $0.13(p=0.68)$ & 0 & 0 \\
\hline Outdoor & 0 & 0.27 & 0 & 0 & 0,25 & 0,22 & 0 & 0 \\
\hline
\end{tabular}

Each value represents the number of bites per person per morning, indoor or outdoor. No significant feeding behaviour according the place of biting was observed for both vector during the dry and the rainy season

a specific circadian rhythm in which blood-feeding activities are preferentially performed during the night [21]. Thus, this daytime biting activity may imply a change in Anopheles circadian rhythms, despite the fact that experimental exposure to light can alter their biting ability [22]. Further investigations are needed to assess the basis of this diurnal biting behaviour, as it is now becoming widespread in Dielmo.

The An. gambiae complex and An. funestus groups are the only malaria vectors involved in Plasmodium transmission, therefore, the HBR and the EIR were evaluated accordingly. Anopheles morning biting activity is marginal compared to the night-time vector activity which is three times higher. Paradoxically, the level of EIR during the morning is twice as high compared to the night. The same trend was observed in Dielmo in 2011, when $A n$. funestus was the sole vector biting humans during the day [9]. However, in this previous study, the level of exposure to vector bites was higher than that observed in this study, during which the incidence of the disease was very low and transmission remained seasonal [23]. Therefore, the EIR evaluated during this study should be interpreted with caution, as the level of exposure to Anopheles during the morning and the night is very low. Nevertheless, this study shows the importance of maintaining a continues entomological surveillance during the whole year in areas dealing with low level of exposure to vector bites and residual malaria transmission [24, 25]. However, incorporating a socio-demographic aspect into control strategies could help to provide better containment for residual transmission as human behaviour contributes greatly to malaria outbreaks in this situation $[3,26]$ and malaria transmission could persist at very low level even during the dry season [27].

During the night, the peak of hourly aggressiveness observed did not change compared to a previous study in Dielmo and remains confined to the second part of the night [7]. This indicates that the population could be protected while resting indoor, as the peaks observed during the night correspond to moments when the population is asleep [7], with a relatively high compliance rate in the use of LLINs [4], unlike the peak that occurs during the morning, when people are awake and remained unprotected by the LLINs. Thus, in areas striving to eliminate malaria, more attention should be paid to the possible Anopheles morning biting activity which essentially takes place indoors and throughout the year, which could maintain residual levels of Plasmodium transmission. In Dielmo, the introduction of a significant healthcare system allowing for rapid diagnosis and malaria case management [28], combined with close entomological monitoring are used to detect and/or prevent outbreaks that can result from this low level of transmission. The increase in Anopheles outdoor biting which was observed after the implementation of LLINs or indoor residual spraying (IRS) in endemic malaria areas $[6,7,29]$, could also sustain the residual transmission of malaria. Indeed, the shift of the Anopheles to outdoor biting, combined with changing human behavior in Dielmo marked by increased outdoor nocturnal activity due to rural electrification could sustainably maintain residual outdoor exposure to vector bites and the occurrence of malaria outbreaks [3].Therefore, controlling outdoor exposure is the current challenge facing malaria control programmes. In this study, it appears that during the night and the morning, An. arabiensis and An. funestus showed no preference for biting outdoor or indoor regardless the season (dry or wet). It shows therefore the complexity of human exposure to Anopheles bites and similar attention should be paid to both the control of indoor and outdoor residual exposure when LLINs are in use [30] and whatever the season. Therefore, a more comprehensive understanding of Anopheles spatiotemporal dynamic and adaptive response to insecticidetreated tools is required to address this issue. In Dielmo area, previous studies showed that the introduction of LLINs induced a shift in the Anopheles population in favour of An. arabiensis which became the dominant species [31]. Furthermore, it induced a temporal and spatial structuration of the An. arabiensis population [32] suggesting a different subpopulation that may have a different pattern of biting. In assition, the adults $A n$. arabiensis issued from a larval population carry $k d r$ alleles despite the fact that this was not associated with resistance to 
pyrethroids [33], while no data regarding An. funestus is available, although its resistance to lambda-cyhalothrin has been recorded elsewhere in Senegal [34].

\section{Conclusion}

In Dielmo, the human population is exposed to low level biting rates from three Anopheles vectors both during the night and at least $11 \mathrm{am}$ in the morning. Despite this low level of exposure, awareness should be reinforced for LLIN use all year round. Taken as a whole, these results suggest that, in addition to the objective of developing complementary tools to control the outdoor biting of Anopheles, greater effort must be made to annihilate the residual daylight aggressiveness that occurs during both the dry and rainy seasons. This suggest the eventuality to assess if the current tools can be implemented to control the morning activity of Anopheles.

\section{Abbreviations}

Bpn: Bite per night; Bpm: Bite per morning; Bph: Bite per hour; CSP: Circumsporozoite Protein; ELISA: Enzyme-Linked Immunosorbent Assay; EIR: Entomological Inoculation Rate; HBR: Human Biting Rate; HLC: Human landing catch; LLINs: Long-lasting insecticidal nets; IMPs: Intentional mismatch primersIRS Indoor residual spraying; IRS: Indoor residual spraying.

\section{Acknowledgements}

We are grateful to the inhabitants of Dielmo for their cooperation.

\section{Authors' contributions}

SD, ND and CS designed the study. SD and ND supervised the study. CB carried out the field collections. OT did the experiments. SD and ANW analysed the data. SD wrote the manuscript. SD, OT, ND, ANW and PP reviewed the final draft. All authors read and approved the final manuscript.

\section{Funding}

This work was supported by the Unité Mixte de Recherche Vecteurs Infections Tropicales et Méditerranéennes (VITROME) Campus UCAD/IRD de Hann, BP 1386. The «Fonds d'Impulsion de la Recherche Scientifique et Technique-FIRST du Ministère de l'Enseignement supérieur et de la Recherche du Sénégal». The funding bodies played no role in the design of the study and collection, analysis and interpretation of data nor in the writing of the manuscript.

\section{Availability of data and materials}

The datasets used and/or analysed during the current study are available from the corresponding author on reasonable request.

\section{Ethics approval and consent to participate}

The study was approved by the Ministry of Health of Senegal and the assembly of the Dielmo population.

\section{Consent for publication}

Not applicable.

\section{Competing interests}

The authors declare that they have no competing interests.

\section{Author details}

${ }^{1}$ VITROME, Campus International UCAD-IRD, Dakar, Sénégal. ${ }^{2}$ Laboratoire d'Ecologie Vectorielle et Parasitaire (LEVP), Faculté des Sciences et Techniques (FST), Université Cheikh Anta Diop (UCAD), Dakar, Sénégal. ${ }^{3}$ Aix Marseille Univ, IRD, AP-HM, SSA, VITROME, Marseille, France. ${ }^{4}$ HUU-Méditerranée Infection, Marseille, France.
Received: 22 April 2020 Accepted: 17 June 2020

Published online: 26 June 2020

\section{References}

1. WHO. World malaria report 2019 [Internet]. Geneva, World Health Organization, 2019 [cited 2020 Jan 20]. https://www.who.int/news-room/featu re-stories/detail/world-malaria-report-2019.

2. WHO. About the WHO Global Malaria Programme [Internet]. Geneva, World Health Organization [cited 2020 Jan 22]. http://www.who.int/malar ia/about_us/en/.

3. Wotodjo AN, Diagne N, Gaudart J, Richard V, Raoult D, Sokhna C. Malaria risk factors in Dielmo, a Senegalese malaria-endemic village, between October and November of 2013: a case-control study. Am J Trop Med Hyg. 2015;92:565-8.

4. Wotodjo AN, Richard V, Boyer S, Doucoure S, Diagne N, Touré-Baldé A, et al. The implication of long-lasting insecticide-treated net use in the resurgence of malaria morbidity in a Senegal malaria endemic village in 2010-2011. Parasit Vectors. 2015;8:267.

5. Carrasco D, Lefèvre T, Moiroux N, Pennetier C, Chandre F, Cohuet A. Behavioural adaptations of mosquito vectors to insecticide control. Curr Opin Insect Sci. 2019;34:48-54.

6. Russell TL, Govella NJ, Azizi S, Drakeley CJ, Kachur SP, Killeen GF. Increased proportions of outdoor feeding among residual malaria vector populations following increased use of insecticide-treated nets in rural Tanzania. Malar J. 2011;10:80

7. Sougoufara S, Thiaw O, Cailleau A, Diagne N, Harry M, Bouganali C, et al. The impact of periodic distribution campaigns of long-lasting insecticidal-treated bed nets on malaria vector dynamics and human exposure in Dielmo. Senegal. Am J Trop Med Hyg. 2018;98:1343-52.

8. Bugoro H, Cooper RD, Butafa C, Iro'ofa C, Mackenzie DO, Chen CC, et al. Bionomics of the malaria vector Anopheles farauti in Temotu Province, Solomon Islands: issues for malaria elimination. Malar J. 2011;10:133.

9. Sougoufara S, Diédhiou SM, Doucouré S, Diagne N, Sembène PM, Harry $\mathrm{M}$, et al. Biting by Anopheles funestus in broad daylight after use of longlasting insecticidal nets: a new challenge to malaria elimination. Malar J. 2014;13:125.

10. Moiroux N, Gomez MB, Pennetier C, Elanga E, Djènontin A, Chandre F, et al. Changes in Anopheles funestus biting behavior following universal coverage of long-lasting insecticidal nets in Benin. J Infect Dis. 2012:206:1622-9.

11. Prussing C, Moreno M, Saavedra MP, Bickersmith SA, Gamboa D, Alava F, et al. Decreasing proportion of Anopheles darlingi biting outdoors between long-lasting insecticidal net distributions in peri-lquitos Amazonian Peru. Malar J. 2018:17:86.

12. Sherrard-Smith E, Skarp JE, Beale AD, Fornadel C, Norris LC, Moore SJ, et al. Mosquito feeding behavior and how it influences residual malaria transmission across Africa. Proc Natl Acad Sci USA. 2019;116:15086-95.

13. Trape JF, Rogier C, Konate L, Diagne N, Bouganali H, Canque B, et al. The Dielmo project: a longitudinal study of natural malaria infection and the mechanisms of protective immunity in a community living in a holoendemic area of Senegal. Am JTrop Med Hyg. 1994;51:123-37.

14. Gillies MT, Coetzee M. A supplement to the Anophelinae of Africa south of the Sahara (Afrotropical Region). Publ South Afr Inst Med Res. 1987;55:1-143

15. Wilkins EE, Howell PI, Benedict MQ. IMP PCR primers detect single nucleotide polymorphisms for Anopheles gambiae species identification, Mopti and Savanna rDNA types, and resistance to dieldrin in Anopheles arabiensis. Malar J. 2006;5:125.

16. Koekemoer LL, Kamau L, Hunt RH, Coetzee M. A cocktail polymerase chain reaction assay to identify members of the Anopheles funestus (Diptera: Culicidae) group. Am J Trop Med Hyg. 2002;66:804-11.

17. Wirtz RA, Ballou WR, Schneider I, Chedid L, Gross MJ, Young JF, et al. Plasmodium falciparum: immunogenicity of circumsporozoite protein constructs produced in Escherichia coli. Exp Parasit. 1987;63:166-72.

18. Fontenille D, Lochouarn L, Diagne N, Sokhna C, Lemasson JJ, Diatta M, et al. High annual and seasonal variations in malaria transmission by anophelines and vector species composition in Dielmo, a holoendemic area in Senegal. Am J Trop Med Hyg. 1997;56:247-53. 
19. Wamae PM, Githeko AK, Otieno GO, Kabiru EW, Duombia SO. Early biting of the Anopheles gambiae and its challenges to vector contro using insecticide treated nets in western Kenya highlands. Acta Trop. 2015;150:136-42.

20. Yohannes M, Boelee E. Early biting rhythm in the Afro-tropical vector of malaria, Anopheles arabiensis, and challenges for its control in Ethiopia. Med Vet Entomol. 2012;26:103-5.

21. Duffield GE, Acri DJ, George GF, Sheppard AD, Beebe NW, Ritchie SA, et al. Diel flight activity of wild-caught Anopheles farauti (s.s.) and An. hinesorum malaria mosquitoes from northern Queensland, Australia. Parasit Vectors. 2019;12:48.

22. Sheppard AD, Rund SSC, George GF, Clark E, Acri DJ, Duffield GE. Light manipulation of mosquito behaviour: acute and sustained photic suppression of biting activity in the Anopheles gambiae malaria mosquito. Parasit Vectors. 2017;10:255.

23. Wotodjo AN, Doucoure S, Gaudart J, Diagne N, Diene Sarr F, Faye N, et al. Malaria in Dielmo, a Senegal village: is its elimination possible after seven years of implementation of long-lasting insecticide-treated nets? PLoS ONE. 2017;12:e0179528.

24. Burkot TR, Bugoro H, Apairamo A, Cooper RD, Echeverry DF, Odabasi D, et al. Spatial-temporal heterogeneity in malaria receptivity is best estimated by vector biting rates in areas nearing elimination. Parasit Vectors. 2018;11:606.

25. WHO. From malaria control to malaria elimination: a manual for elimination scenario planning [Internet]. Geneva, World Health Organization [cited 2020 Jan 30]. http://www.who.int/malaria/publications/atoz/97892 41507028/en/.

26. Chuquiyauri R, Paredes M, Peñataro P, Torres S, Marin S, Tenorio A, et al. Socio-demographics and the development of malaria elimination strategies in the low transmission setting. Acta Trop. 2012;121:292-302.

27. Niang M, Thiam LG, Sane R, Diagne N, Talla C, Doucoure S, et al. Substantial asymptomatic submicroscopic Plasmodium carriage during dry season in low transmission areas in Senegal: Implications for malaria control and elimination. PLOS ONE. 2017;12(8):e0182189.

28. Sokhna C, Basséne H, Diatta G, Diagne N, Doucouré S, Diallo A, et al. The University Hospital Institute Mediterrannée Infection from Marseille to Dakar. Med Sante Trop. 2019;29:354-60.

29. Russell TL, Beebe NW, Bugoro H, Apairamo A, Collins FH, Cooper RD, et al. Anopheles farauti is a homogeneous population that blood feeds early and outdoors in the Solomon Islands. Malar J. 2016;15:151.

30. Bayoh MN, Walker ED, Kosgei J, Ombok M, Olang GB, Githeko AK, et al. Persistently high estimates of late night, indoor exposure to malaria vectors despite high coverage of insecticide treated nets. Parasit Vectors. 2014;7:380.

31. Sougoufara S, Harry M, Doucouré S, Sembène PM, Sokhna C. Shift in species composition in the Anopheles gambiae complex after implementation of long-lasting insecticidal nets in Dielmo Senegal. Med Vet Entomol. 2016;30:365-8.

32. Sougoufara S, Sokhna C, Diagne N, Doucouré S, Sembène PM, Harry M. The implementation of long-lasting insecticidal bed nets has differential effects on the genetic structure of the African malaria vectors in the Anopheles gambiae complex in Dielmo, Senegal. Malar J. 2017;16:337.

33. Thiaw O, Doucouré S, Sougoufara S, Bouganali C, Konaté L, Diagne N, et al. Investigating insecticide resistance and knock-down resistance ( $k d r)$ mutation in Dielmo, Senegal, an area under long lasting insecticidaltreated nets universal coverage for 10 years. Malar J. 2018;17:123.

34. Samb B, Konate L, Irving H, Riveron JM, Dia I, Faye O, et al. Investigating molecular basis of lambda-cyhalothrin resistance in an Anopheles funestus population from Senegal. Parasit Vectors. 2016;9:449.

\section{Publisher's Note}

Springer Nature remains neutral with regard to jurisdictional claims in published maps and institutional affiliations.
Ready to submit your research? Choose BMC and benefit from:

- fast, convenient online submission

- thorough peer review by experienced researchers in your field

- rapid publication on acceptance

- support for research data, including large and complex data types

- gold Open Access which fosters wider collaboration and increased citations

- maximum visibility for your research: over $100 \mathrm{M}$ website views per year

At BMC, research is always in progress.

Learn more biomedcentral.com/submissions 